RESEARCH REPORT

\title{
COMPARE THE EFFECT OF BODY WEIGHT SUPPORTED TREADMILL TRAINING WITH OVERGROUND GAIT TRAINING ON BALANCE IN SPASTIC CEREBRAL PALSY
}

\begin{abstract}
\section{OBJECTIVE}

Compare the effect of body weight supported treadmill training with over ground gait training on balance in spastic cerebral palsy.

STUDY DESIGN

Randomized Control Trail

STUDY SETTINGS \& PARTICIPANTS

This study was conducted in a Rehabilitation Centre. Twenty eight participants were recruited, fifteen in experimental group and thirteen in control group. All participants were spastic and classified I, II \& III at GMCFS.

INTERVENTIONS

Treatment was given for three days in a week for consecutive period of six weeks which includes BWSTT and overground gait training

\section{OUTCOME MEASURES}

The outcome was measured by using Berg Balance Scale, Brunel Balance Scale, TUG, and TST and Timed 360 Turn.

RESULTS

Both the techniques shown positive results but BWSTT had shown better result with the mean improvement in Berg Balance Scale

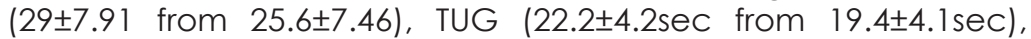
Brunel Balance Scale (7.4 \pm 2.34 from 6.27 \pm 2.52$)$, TST (5.73 \pm 1.6 from $4.07 \pm 1.58)$ \& Timed 360 Turn $(9.4 \pm 2.02 \mathrm{sec}$ to $7.87 \pm 2.23 \mathrm{sec})$ with comparison to control group which had a mean improvement in Berg Balance Scale (28.08 \pm 7.11 from 26.38 \pm 7.14$)$, TUG (21.46 \pm 4.0 sec from 19.54 \pm 3.79$)$, Brunel Balance Scale $(7.31 \pm 2.32$ from $6.54 \pm 2.60), \mathrm{TST}(5.46 \pm 1.56$ from $4.31 \pm 1.54)$ \& Timed 360 Turn $(9.23 \pm 1.69 \mathrm{sec}$ to $7.85 \pm 1.67 \mathrm{secs})$.
\end{abstract}

\section{CONCLUSION}

It has concluded that the BWSTT is more effective than the overground gait training in improving the balance of spastic cerebral palsy, however more studies should be conducted to validate the effects of BWSTT among Cerebral Palsy.

\section{KEYWORDS}

Cerebral Palsy, Body Weight Supported Treadmill Training, Spastic CP, Balance, Berg Balance Scale, Gait

\author{
Abid Khan \\ Lecturer \\ Ziauddin College of Physical Therapy \\ Ziauddin University \\ abid_khan6630@hotmail.com \\ Sumaira Imran Farooqui \\ Associate Professor, Principal \\ Ziauddin College of Physical Therapy \\ Ziauddin University \\ sumairaimranfarooqui@g- \\ mail.com

\section{Amna Aamir Khan Assistant Professor Ziauddin College of Physical Therapy Ziauddin University akhan39@caledonian.ac.uk}

[Khan A, Farooqui SI, Khan AA. Compare the Effect of Body Weight Supported Treadmill Training With Overground Gait Training on Balance in Spastic Cerebral Palsy. Pak. j. rehabil. 2016;5(2):25-31] 


\section{INTRODUCTION}

Cerebral Palsy is a non-progressive, permanent brain lesion of immature brain common in 2 per 1000 children $^{1,2}$. The prevalence of CP has remained remarkably stable over the last 30 years $^{3}$. $80 \%$ of cerebral palsy is spastic, causing limitations in activities of daily livings, impairment in motor function, gait and balance ${ }^{4}$. The upper motor neuron lesion in the brain damages the functionality of nerve receptors in the spine to properly receive Gamma Amino Butyric Acid (GABA). Which intern leads to hypertonia of the muscle supplied by those damaged nerves, this condition is known as spasticity. Spasticity is of various types in which diplegic is most common. The spastic diplegic are ambulatory with abnormalities like excessive planter flexion at ankle joint and excessive knee flexion associated with adduction and internal rotation at hip joint, these abnormalities influence the static and dynamic balance $^{5}$. To assess the balance among the cerebral palsy patients is a complex task which includes several functional tests but the most common are Berg Balance Scale $(\mathrm{BBS})^{6}$, Bruininks-Oseretsky Test of Motor Proficiency (BOTMP) ${ }^{7}$ and Timed Up and Go (TUG) all of these 8 constitute the most frequently applied control tests for the quantitative changes in balance.

Maintaining posture is an essential task for balance control in the children with cerebral palsy. It is complicated activity to maintain body weight within the base of support during standing, sitting, walking and performing activity 9,10 . Postural control is determined by vision integration, proprioceptive sensation, vestibular and commands from brain ${ }^{11,12}$. Postural instability constitute the major impairment in motor development, these children shown number of limitation while performing dynamic and static activities ${ }^{13}$.

With a growing body of re efficacy of treadmill training for training for adults with neurologic disorders, most notably after spinal cord injury, clinicians and researchers in the field of pediatric CP have begun to turn their attention to the potential of treadmill training for improving walking in children with CP. This interest is based on the principle that task-specific and repetitive practice is required to develop and improve a motor skill such as walking $^{6-9}$. Use of mechanical treadmill, with or without body weight support may improve walking in children with CP because it provides an opportunity to repetitively and intensively train the whole gait cycle and facilitate an improved gait pattern during walking. Preliminary work suggest that body weight supported treadmill training (BWSTT) is feasible in children with $\mathrm{CP}$ and may improve their walking speed, walking endurance and general gross motor skills ${ }^{10-14}$.

Some authors have revealed the effects of BWSTT among spastic $\mathrm{CP}^{14-21}$. One author assured the effects on ten children in a 12 week program in which there were three spastic diplegic and spastic quadriplegic and four were spastic quadriplegic with a mean age of 11 years and 6 months, after intervention there was a significant improvement noted in Gross Motor Function and in ambulation as compare to the baseline assessment ${ }^{14,22,23}$. In another research, where six participant in which four were spastic diplegic, one was spastic hemiplegic and one was athetiod quadriplegic. A 12 week BWSTT program was intervened which revealed the significant improvement in on ground walking speed meanwhile the energy expenditure showed no significant change. Six other articles revealed improvement in independent walking, walking endurance and waling speed ${ }^{16-20}$. However above mentioned studies fail to prove any effect on Postural control which is an important component of independent walking and motor functioning.

The primary aim of the present study is to evaluate the effect of treadmill training with body weight support on functional, dynamic and static balance in CP children, using a comparative analysis of training with on ground gait training and determine whether the effects last after the interruption of interventions. Secondary aim is to determine the functional outcomes of treadmill training on balance among Pakistani population.

\section{METHODOLOGY}

\section{Inclusion Criteria}

Age between 5-14 years, spastic cerebral palsy, Gross Motor Function Classification as $1,2,3$ by GMFCS and participant must walk independently with or without assistive devices.

\section{Exclusion Criteria}

Children submitted to orthopedic surgical procedures or neuromuscular block in the 12 months prior to the training sessions and those with orthopedic deformity with indication for surgery were excluded from the study.

\section{Participants}

The individuals were recruited and selected for eligibility using the inclusion and exclusion criteria. After fulfilling the eligibility criteria and undergoing the initial evaluation, the participants were randomly distributed into an experimental group (gait training on a moving surface (treadmill)) and an over ground walking group (gait training on a fixed surface (ground)). Randomization was performed at rehabilitation center. We used a randomization table .using sealed, set of numbered envelopes to maintain confidentiality.

\section{Apparatus}

A motorized treadmill (Hydro Fitness Motorized Treadmill HF-C10), having a emergency stop button 
and a pause button. The treadmill can measure the distance and time displayed at a digital screen during sessions, was used in study. The treadmill had minimal speed of $0.1 \mathrm{~km}$ per hour. Body weight support was given through Walk Able. The Walk Able is comprised of a harness that supports the lower trunk and pelvis. The system was suspended vertically and had horizontal bars which were positioned directly over the child's head. The system has lockable castors.

\section{Outcome Measures}

For assessing functional balance we used Berg balance scale, which is consisting of 14 tasks similar to different ADL. The scale contains five points $(0,1$, 2, 3 or4) zero indicates inability to perform activity without assistance and four shows doing activity independently. TUG time up go test can also be used to assess functional balance in which subject is seated with back support is commanded to stand up and reach to the marked point at 3 meters turn around and come back to the seat and sit with back support this all procedure will take less than 10 seconds. Performing TUG test in more than 10 seconds predict a poor balance ${ }^{14}$. For dynamic balance we used the timed 360 turn, in which individual turn 360 while stepping ${ }^{15}$. For assessing the static balance we use Tandem Stance Test (TST). Individuals will stand with narrow base of support and maintain the upright balance without taking step $^{16}$. Brunel Balance Assessment is the most valid and reliable assessments of static balance in different states like sitting, standing, single leg stance etc $^{17,18}$

\section{Procedure}

The training program was implemented at Rehabilitation Association. Each child was matched for sex, age, type of CP and GMFCS level. After assessing the participants at their baseline, six week trice weekly session of BWSTT conducted under the supervision of senior physiotherapist, who had to conduct all the sessions. The participants are allowed to wear their usual orthosis and they were allowed to use the assistive devices where required. Participants were adjusted with the apparatus; they wore the harness so that it gives the support at the pelvis and lower trunk. Treadmill was set according to the participant so that the participant can place foot with comfortably. Speed was generally increased with the increments of $0.1 \mathrm{~km} / \mathrm{h}$. During the session physiotherapist can provide the assistance where required during the swing phase. The study comprises of two groups; Group A and Group B, Group A is experimental Group and Group $B$ is Control Group.

Group A had given Body Weight Support Treadmill Training for six weeks three sessions per week. The protocol of the training program comprises of familiarization period for two weeks which allow partici- pants to get familiarized with the treadmill and exercise programs the period are not be counted. The session starts with the warm up period for 5 minutes in which the participant will walk up to the $60 \%$ of Targeted Heart Rate the next step is the period of conditioning in which the participant will run on a treadmill up to the targeted heart rate of $80 \%$ for a period of twenty minutes and finally the cool down period of five minutes before the end of session.

Group B had given Over Ground Gait Training for six weeks three sessions per week. The protocol of the training program comprises of familiarization period for two weeks which allow participants to get familiarized with exercise programs the period are not be counted. The session starts with the warm up period for 5 minutes in which the participants have walked up to $60 \%$ of Targeted Heart Rate followed by walk up to $80 \%$ Targeted Heart Rate for 20 minutes and finally the cool down period of 5 minutes before the end of session. The vitals are monitored throughout the session using pulse Oximeter and the assessment form has filled by the researcher before and after the session.

Participants were allowed to continue their normal ADLs. Such as physical activity programs where they usually used to participated in. physiotherapists which were involved in the therapy session of participants were advised not to increase the intensity of gait training the physical therapy sessions.

\section{RESULTS}

Thirty five children were recruited and their progression through the trial of the thirty five participants assessed at the baseline, four in the experimental group and three in the control group withdrew after completing only 2 to 4 training sessions.

Adherence to training was similar between groups. Of a total of 18 sessions, the control group attended a mean of $14.21 \pm 2.19$ sessions and the experimental group attended a mean of $13.33 \pm 2.02$ sessions. Nonattendance was mostly because of illness (50 sessions), participation in school excursions (14 sessions) or public holidays (6 sessions). No session was missed because of adverse events related to training.

Both groups have shown a significant improvement in post evaluation with the $(P<0.05)$ and the mean differences are discus below. Meanwhile follow up of month also shown significant results shown in fig 1 \& 2 .

\section{Effects of Intervention}

\section{A. Functional Balance}

For assessing the functional balance we used Berg Balance Scale and Time Up and Go test. 
- Berg Balance Scale:

Analysis by using Paired Sample Test revealed a statistically significant improvement in an experimental group with a mean improvement of $29 \pm$ 7.91 from 25.6 \pm 7.46 in Berg Balance Scale as compare to control group where slight improvement has been observed with the mean of $28.08 \pm 7.11$ from
26.38 \pm 7.148 . The effects of intervention in an experimental group has also been observed in one month follow up protocol with the mean of $27.27 \pm 7.58$ from 25.6 \pm 7.46 , whereas there was slight significant improvement in control group where mean is $26.77 \pm 7.143$ from $26.38 \pm 7.148$.

\section{Figure 1}

Experimental group:

\begin{tabular}{|c|c|c|c|c|c|c|c|c|c|}
\hline & & \multicolumn{5}{|c|}{ Paired Differences } & \multirow[t]{3}{*}{$t$} & \multirow{3}{*}{$d f$} & \multirow{3}{*}{$\begin{array}{l}\text { Sign. (2- } \\
\text { tailed) }\end{array}$} \\
\hline & & \multirow[t]{2}{*}{ Mean } & \multirow[t]{2}{*}{$\begin{array}{c}\text { Std. } \\
\text { Deviation }\end{array}$} & \multirow[t]{2}{*}{$\begin{array}{l}\text { Std. Error } \\
\text { Mean }\end{array}$} & \multicolumn{2}{|c|}{$\begin{array}{l}\text { 95\% Confidence Interval } \\
\text { of the Difference }\end{array}$} & & & \\
\hline & & & & & Lower & Upper & & & \\
\hline Pair 1 & $\begin{array}{l}\text { Time } 360 \text { turn post- Time } \\
360 \text { turn } 1 \text { month }\end{array}$ & -1.385 & .506 & .140 & -1.691 & -1.079 & -9.859 & 12 & .000 \\
\hline Pair 2 & $\begin{array}{l}\text { Tandem stance post- } \\
\text { Tandem stance } 1 \text { month }\end{array}$ & 1.077 & .641 & .178 & .690 & 1.464 & 6.062 & 12 & .000 \\
\hline Pair 3 & $\begin{array}{l}\text { Brunel Balance post-Brunel } \\
\text { Balance } 1 \text { month }\end{array}$ & .615 & .650 & .180 & .222 & 1.008 & 3.411 & 12 & .005 \\
\hline Pair 4 & $\begin{array}{l}\text { Time up and go post- Time } \\
\text { up and go } 1 \text { month }\end{array}$ & -1.154 & 1.068 & .296 & -1.799 & -.508 & -3.895 & 12 & .002 \\
\hline Pair 5 & $\begin{array}{l}\text { Berg balance scale post- } \\
\text { Berg balance scale } 1 \text { month }\end{array}$ & 1.308 & .751 & .208 & .854 & 1.762 & 6.278 & 12 & .000 \\
\hline
\end{tabular}

\section{Figure 2}

Controlled group:

\begin{tabular}{|c|c|c|c|c|c|c|c|c|c|}
\hline & \multicolumn{5}{|c|}{ Paired Differences } & \multirow{3}{*}{$\dagger$} & \multirow{3}{*}{$d f$} & \multirow{3}{*}{$\begin{array}{l}\text { Sign. (2- } \\
\text { tailed) }\end{array}$} \\
\hline & & \multirow[t]{2}{*}{ Mean } & \multirow[t]{2}{*}{$\begin{array}{c}\text { Std. } \\
\text { Deviation }\end{array}$} & \multirow[t]{2}{*}{$\begin{array}{l}\text { Std. Error } \\
\text { Mean }\end{array}$} & \multicolumn{2}{|c|}{$\begin{array}{l}\text { 95\% Confidence Interval } \\
\text { of the Difference }\end{array}$} & & & \\
\hline & & & & & Lower & Upper & & & \\
\hline Pair 1 & $\begin{array}{l}\text { Berg balance scale post- } \\
\text { Berg balance scale } 1 \text { month }\end{array}$ & 1.308 & .751 & .208 & .854 & 1.762 & 6.278 & 12 & .000 \\
\hline Pair 2 & $\begin{array}{l}\text { Time } 360 \text { turn post- Time } 360 \\
\text { turn } 1 \text { month }\end{array}$ & -1.385 & .506 & .140 & -1.691 & -1.079 & -9.859 & 12 & .000 \\
\hline Pair 3 & $\begin{array}{l}\text { Tandem stance post- } \\
\text { Tandem stance } 1 \text { month }\end{array}$ & 1.77 & .641 & .178 & .690 & 1.464 & 6.062 & 12 & .000 \\
\hline Pair 4 & $\begin{array}{l}\text { Brunel Balance post- Brunel } \\
\text { Balance } 1 \text { month }\end{array}$ & .615 & .650 & .180 & .222 & 1.008 & 3.411 & 12 & .000 \\
\hline Pair 5 & $\begin{array}{l}\text { Time up and go post- Time } \\
\text { up and go } 1 \text { month }\end{array}$ & -1.154 & 1.068 & .296 & -1.799 & -.508 & -3.895 & 12 & .000 \\
\hline
\end{tabular}


- Time Up and Go:

Statically analysis by using Paired Sample Test has shown that after 18 sessions of treadmill training in experimental group the functional balance has significantly improved with mean from $22.2 \pm 4.2$ seconds to $19.4 \pm 4.1$ seconds in comparison to control group where slight improvement has been observed from $21.46 \pm 4.0$ seconds to $19.54 \pm 3.79$ seconds and moreover one month follow up protocol also shown improvement in both groups in experimental group and in control group. As mention in table 1

\section{Table 1}

\begin{tabular}{|c|c|c|c|c|c|c|}
\hline Scale & \multicolumn{3}{|c|}{ Experimental Group } & \multicolumn{3}{c|}{ Control Group } \\
\hline \multirow{4}{*}{ BBS } & Pre & Post & Follow up & Pre & Post & Follow up \\
\cline { 2 - 7 } & $25.6 \pm 7.4$ & $29 \pm 7.91$ & $27.27 \pm 7.5$ & $26.3 \pm 7.1$ & $28.08 \pm 7.1$ & $26.77 \pm 7.1$ \\
\cline { 2 - 7 } TUG & $22.2 \pm 4.2$ & $19.4 \pm 4.1$ & $20.5 \pm 3.8$ & $21.4 \pm 4.0$ & $19.54 \pm 3.79$ & $20.6 \pm 3.6$ \\
\hline
\end{tabular}

\section{B. Static Balance}

For assessing the static balance of spastic cerebra palsy we used Brunel Balance Scale and Tandem Stance Test.

\section{- Brunel Balance Scale:}

Intervention on experimental group has shown significant improvement on the static balance of spastic cerebral palsy on Brunel Balance Scale. Eighteen sessions of intervention using body weight support treadmill training improved the balance by using Paired Sample Test almost a mean of 7.4 \pm 2.34 from 6.27 \pm 2.52 . Improvement has also been observed in control group with a mean of $7.31 \pm 2.32$ from 6.54 \pm 2.60 . In a follow up protocol experimental group has shown slight improvement mean of almost $7.07 \pm 2.08$ from $6.27 \pm 2.52$, whereas control group has shown no significant improvement in a follow up protocol with a mean of $6.69 \pm 2.56$ from $6.54 \pm 2.60$.

\section{- Tandem Stance Test:}

In this study experimental group has shown slight change on the static balance of spastic cerebral palsy in tandem stance test by using Paired Sample

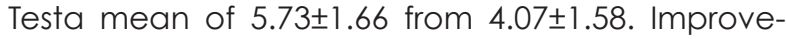
ment has also been observed in control group with a mean of $5.46 \pm 1.56$ from $4.31 \pm 1.54$. Meanwhile the data of follow up protocol showed no significant change in both groups. As mentioned in table 2

\section{Table 2}

\begin{tabular}{|l|c|c|c|c|c|c|}
\hline Scale & \multicolumn{2}{|l|}{ Experimental Group } & \multicolumn{3}{c|}{ Control Group } \\
\hline & Pre & Post & Follow up & Pre & Post & Follow up \\
\cline { 2 - 7 } & $25.6 \pm 7.4$ & $29 \pm 7.91$ & $27.27 \pm 7.5$ & $26.3 \pm 7.1$ & $28.08 \pm 7.11$ & $26.77 \pm 7.1$ \\
$\begin{array}{l}\text { TST } \\
\text { Brunel } \\
\text { Balance }\end{array}$ & $22.2 \pm 4.2$ & $19.4 \pm 4.1$ & $20.5 \pm 3.8$ & $21.4 \pm 4.0$ & $19.54 \pm 3.79$ & $20.6 \pm 3.6$ \\
\hline
\end{tabular}

\section{Dynamic Balance}

For assessing dynamic balance we used Timed 360 Turn

\section{- Timed 360 Turn:}

Data analysis by using Paired Sample Test of experimental group revealed the significant improvement in dynamic balance calculated on Timed 360 Turn Test with a mean of $9.4 \pm 2.02$ seconds to $7.87 \pm 2.23$ seconds. The data of control group has also shown improvement with a mean of $9.23 \pm 1.69$ seconds to $7.85 \pm 1.67$ seconds. Meanwhile the experimental group has shown improvement in follow up protocol with a mean of $9.4 \pm 2.02$ to $8.53 \pm 3.22$, whereas the control group remained unchanged.

\section{DISCUSSION}

The purpose of this study was to analyze the effects of BWSTT with a comparison over ground gait training results. Twenty eight children adequately completed the protocol in three-weekly gait training, static and dynamic balance. However, better results were achieved in treadmill training. Figure 1 unlike the previous studies ${ }^{22-24}$ the present study analyzed the effects of body weight support treadmill training in spastic CP children. The previous studies have concluded that over ground training is proved to be more effective in improving the functional balance of the children suffering from spastic cerebral palsy ${ }^{25-29}$. The result of the present study have shown that the body weight supported treadmill training has found to be more effective as compared to the conventional over ground gait training as shown in Figure 1

\section{Figure 1}

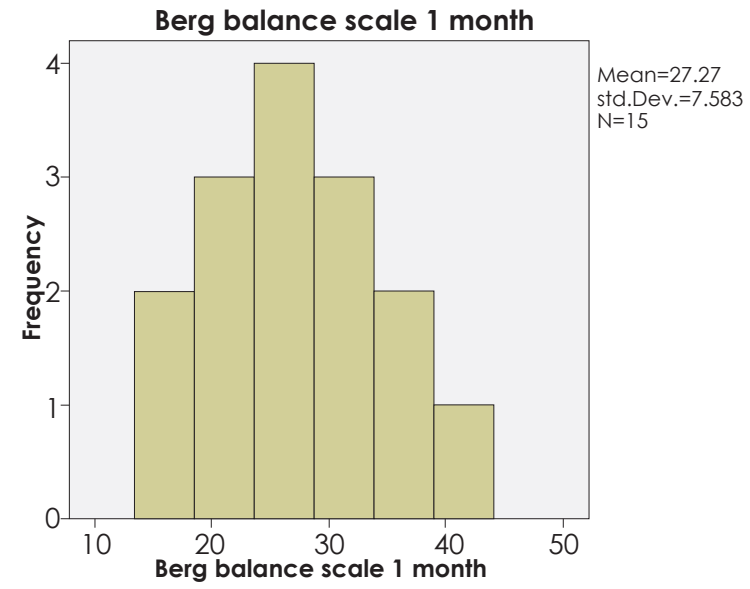

Moreover the body weight supported treadmill training program is found to be effective in month follow up protocol as shown in figure 2 
Figure 2

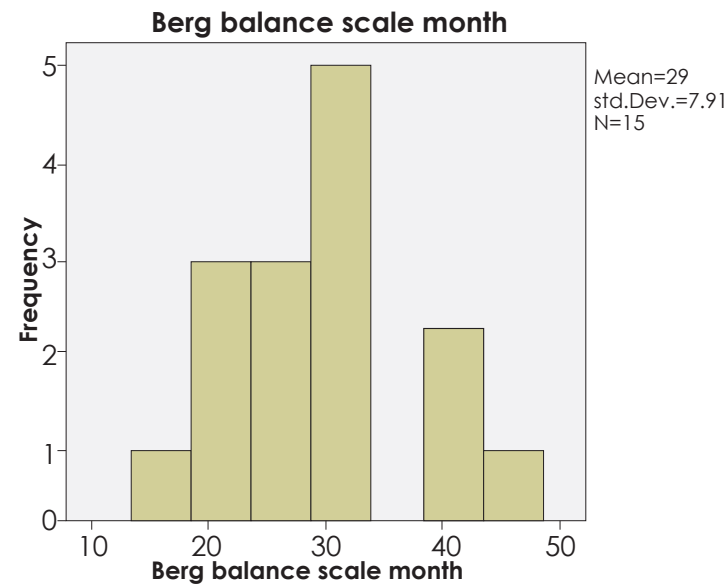

The study conducted by Harkema $\mathrm{SJ}^{30}$, revealed that 14 sessions of treadmill training improved the static and functional balance of a spastic cerebral palsy patients the result is in accordance with the current study in which the 18 sessions of body weight support treadmill training program significantly improve the static balance of a children suffering from cerebral palsy not only in short run but improvement is also be seen in one month follow up protocol session.

The study conducted by Kate L. Willoughby ${ }^{31}$ concluded that body weight supported treadmill training has no effect on walking speed, endurance and dynamic balance whereas this study provides significant evidence that the body weight support treadmill training is effective in improving dynamic balance of a spastic cerebral palsy children not only in a short run but also in a one month follow up protocol.

\section{CONCULSION}

In a nutshell the study has concluded that body weight supported treadmill training is found to be more effective in improving functional, dynamic and static balance of spastic cerebral palsy children in comparison to a conventional over ground gait training program. However the present study has also some limitations and therefore it is suggested that more studies should be conducted to evaluate the effects of body support treadmill training program.

\section{REFERENCES}

[1] Rosenbaum P, Paneth N, Leviton A, Goldstein M, Bax M, Damiano D, et al. A report: the definition and classification of cerebral palsy April 2006. Dev Med Child Neurol Suppl. 2007;109:8-4

[2] Bax M, Goldstein M, Rosenbaum P, Leviton A, Paneth N, Dan B, et al, the Executive Committee for the Definition of Cerebral Palsy.
Proposed definition and classification of cerebral palsy, April 2005. Dev Med Child Neurol. 2005;47(8):571-576

[3] Chagas PSC, Mancini MC, Barbosa AP, Silva PTG. Analysis of the interventions used for gait promotion in children with cerebral palsy: a systematic review of the literature. Rev Bras Fisioter. 2004;8(2):155-163

[4] Graham hk. Botlium toxin-a cerebral palsy functional outcomes j pediatr 2000;13(7):300-303

[5] Bjornson K, Hays R, Graubert C, Price R, et al. Botilium toxin for spasticity in cerebral palsy: a comprehensive evaluation; pediatrics 2007; 120(1):49-58

[6] Berg KO, Wood-Dauphinee SL, Williams JI, Maki B. Measuring balance in the elderly: validation of an instrument. Can J Public Health. 1992;83(2):S7-S1 1

[7] Bruininks RH. Examiner's manual, Bruininks-Oseretsky Test of Motor Proficiency. American Guidance Service, Circle Pines, Minnesota, 1978.

[8] Podsiadlo D, Richardson S. The timed "Up \& Go": a test of basic functional mobility for frail elderly persons. J Am GeriatrSoc 1991;39:142-148

[9] De Kegel A, Dhooge I, Peersman W, Rijckaert J, Baetens T, Cambier D, et al. Construct validity of the assessment of balance in children who are developing typically and in children with hearing impairments. Phys Ther. 2010:90(12):1783-1794

[10] Overstall P. The use of balance training in elderly people with falls. Rev Clin Gerontol. 2003;13(02):153-161

[11] Swanenburg J, De Bruin ED, Favero K, Uebelhart $D$, Mulder T. The reliability of postural balance measures in single and dual tasking in elderly fallers and non-fallers. BMC Musculoskelet Disord. 2008;9(9):162

[12] Nashner LM, Black FO, Wall C 3rd. Adaptation to altered support and visual conditions during stance: patients with vestibular deficits. J Neurosci. 1982;2(5):536-44

[13] Rose J, Wolff DR, Jones VK, Bloch DA, Oehlert JW, Gamble JG. Postural balance in children with cerebral palsy. Dev Med Child Neurol. 2002;44(1):58-63

[14] Iatridou G, Dionyssiotis Y. Reliability of balance evaluation in children with cerebral palsy. Hippokratia 2013;17(4):303-306

[15] Gill TM, Williams CS, Tinetti ME. Assessing risk for the onset of functional dependence among older adults: the role of physical performance. J Am Geriatr Soc. 1995; 43:603-609

[16] Guralnik JM, Simonsick EM, Ferrucci L, et al. A short physical performance battery assessing lower extremity function: association with self-reported disability and prediction of mortality and nursing home admission. J Gerontol. 1994:49(2):M85-94

[17] Blaszczyk JK, Orawiec R, Duda-Klodowska D, 
Opala G. Assessment of postural instability in patients with Parkinson 1s disease. Exp Brain Res. 2007;183:107-114

[18] Dodd KJ, Foley S. Partial body-weight-supported treadmill training can improve walking in children with cerebral palsy: a clinical controlled trial. Dev Med Child Neurol 2007; 49(2):101-105

[19] Mattern-Baxter K. Effects of partial body weight supported treadmill training on children with cerebral palsy. Pediatr Phys Ther 2009;21 (1):12-22

[20] Richards CL, Malouin F, Dumas F, Marcoux S, Lepage $C$, Menier $C$. Early and intensive treadmill locomotor training for young children with cerebral palsy: A feasibility study. Pediatric Phys Ther. 1997:9(4):158-165

[21] Damiano DL, DeJong, SL. A systematic review of the effectiveness of treadmill training and body weight support in pediatric rehabilitation. J Neurol Phys Ther. 2009;33(1):27-44

[22] Palisano R, Rosenbaun P, Walter S, Russel S, Wood E, Galuppi B. Development and reliability of a system to classify gross motor function in children with cerebral palsy. Dev Med Child Neurol. 1997;39(4):214-223

[23] Long TM, Toscano K. Handbook of pediatric physical therapy. 2nd ed. Philadelphia: Lippincott Williams \& Wilkins; 2001

[24] Armijo-Olivo S, Warren S, Magee D. Intention to treat analysis, compliance, drop-outs and how to deal with missing data in clinical research: a review. 2009; 14(1):36-49

[25] Hollis $S$, Campbell F. What is meant by intention to treat analysis? Surveys of published randomized controlled trials. BMJ 1999;319:670-674

[26] Shoa J, Zhong B. Last observation carry forward and last observation analysis. Stat Med 2003;22(15):2429-2441

[27] Cohen J. Statistical power analysis for the behavioral sciences. 2nd ed. New York: Academic Press; 1977

[28] Behrman AL, Harkema SJ. Physical rehabilitation as an agent for recovery after spinal cord injury. Phys Med Rehabil Clin N Am. 2007;18(2):183-202

[29] Behrman AL, Lawless-Dixon AR, Davis SB, et al. Locomotor training progression and outcomes after incomplete spinal cord injury. Phys Yher. 2005;85(12):1356-1371

[30] Harkema SJ. Neural plasticity after human spinal cord injury: application of locomotor training to the rehabilitation of walking. Neuroscientist. $2001 ; 7(5): 455-468$

[31] Willoughby KL, Dodd KJ, Shields N, Foley S. Efficacy of Partial Body Weight-Supported Treadmill Training Compared with Overground Walking Practice for Children With Cerebral Palsy. Arch Phys Med Rehabil. 2010;91(3):333-339 